\section{Removal of Razor Blades from Stomach with Fibreoptic Endoscope}

\author{
L. WITZEL, \\ F. HALTER

\section{U. SCHEURER, A. MÜHLEMANN,}

British Medical fournal, 1974, 2, 539

The risk of intestinal perforation by solid foreign bodies depends on their size and shape (Spitz, 1971). Objects of over $5 \mathrm{~cm}$ diameter, those which do not appear to have moved forward on successive $x$-ray films, and especially sharp or pointed objects such as needles or razor blades should be considered for removal (Jackson and Jackson, 1951; Perelman, 1962; Murat, et al., 1969). Laparotomy has been the only reasonable method for removal of intragastric foreign bodies though retrieval of such objects by means of fibreoptic endoscopy has been reported (Ottenjann, 1970; Spitz, 1971; Maimon and Milligan, 1972; Rösch and Classen, 1972).

We repont a case in which several half-razor-blades were removed with the fibrescope using a special technique. To our knowledge this is the first such report.

\section{Case Report}

A 30-year-old male prisoner was admitted to the department of surgery for the removal of razor blades which he had swallowed. Previously he had undergone laparotomy and gastrotomy to remove a battery and razor blades.

Lateral $x$-ray examination showed several fragments in the stomach and removal of these by endoscopy was attempted. A plastic tube $(80 \mathrm{~cm}$ long, inner diameter $15 \mathrm{~mm})$ was slipped over the proximal part of the ACMI 7089 panendoscope and the assembly was introduced under general anaesthesia. Half of a razor blade was seen in the gastric fundus but an attempt to seize it with the biopsy forceps failed. This forceps was then replaced by a Storz polypectomy snare. With this instrument the fragment was seized and withdrawn together with the fibrescope, while the plastic tube was left in situ (figs. 1 and 2). Altogether six razor blade fragments were removed. Gastroscopy showed no remaining fragments.

\section{Comment}

Some $60-80 \%$ of all swallowed foreign bodies pass through the gastrointestinal tract spontaneously (Perelman, 1962; Spitz, 1971). The time required for passage depends on their shape, round objects passing faster (Spitz, 1971). Pointed objects cause perforation in $35-40 \%$ of cases (Franke et al., 1969). As the ingestion of such objects is not always admitted by the patient the diagnosis can be extremely difficult. Abdominal pain, septicaemia, peritoneal abscess, urinary tract symptoms due to perforation into a kidney, or diarrhoea due to enteroen-

\begin{tabular}{l}
\hline University of Berne, 3010 Berne, Switzerland \\
L. WITZEL, M.D., Senior Registrar \\
U. SCHEURER, M.D., Research Assistant \\
A. MUHLEMANN, M.D., Senior Registrar \\
F. HALTER, M.D., Consultant Gastroenterologist \\
\hline
\end{tabular}

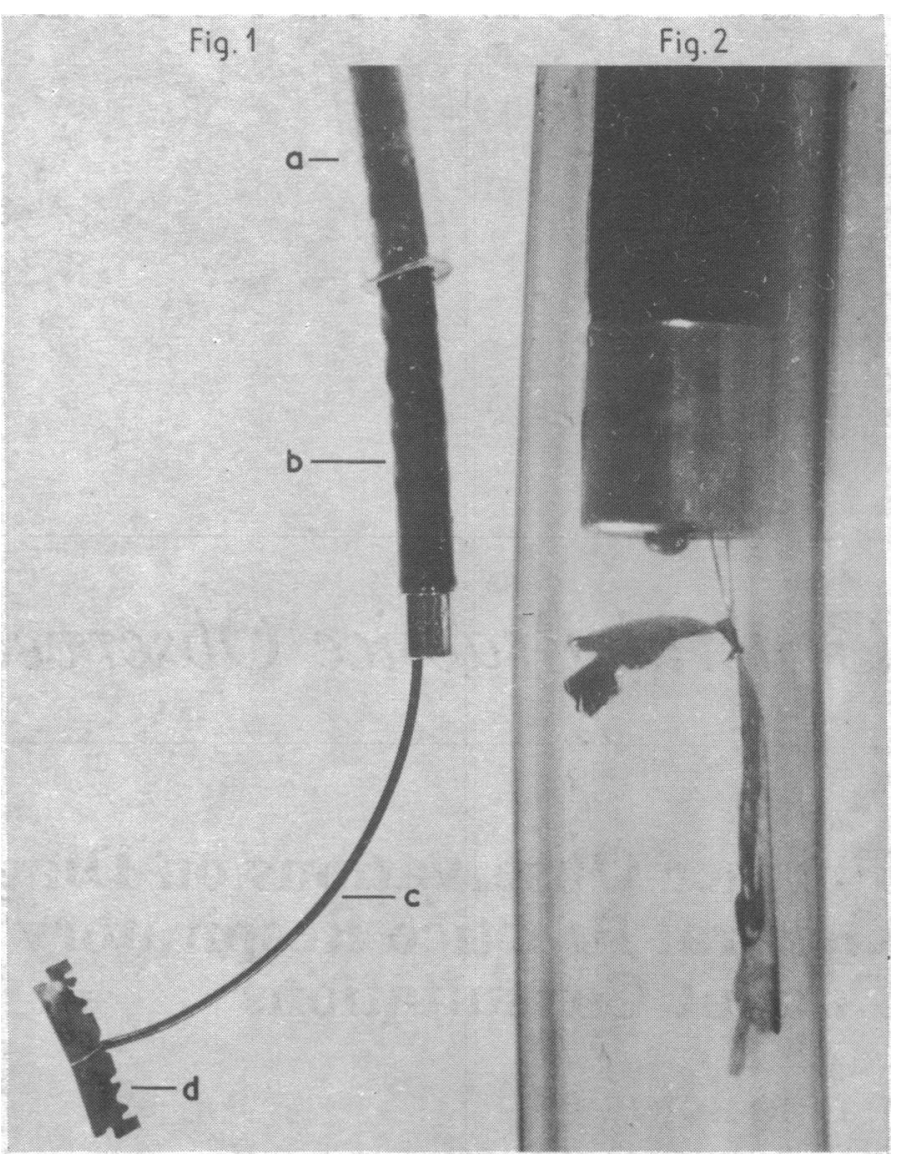

FIG. $1-a=$ Plastic hose. $b=$ Tip of gastroduodenoscope (ACMI 7089). $\mathrm{c}=$ Polypectomy snare. $\mathrm{d}=$ Seized fragment of razor blade. FIG. 2-Razor blade and tip of instrument withdrawn into protecting plastic hose.

teric fistula formation may be the first sign (Spitz, 1971; Maimon and Milligan, 1972). Such complications can be prevented only by early removal of intragastric foreign bodies. The technique described here allows this to be achieved with all objects unless their size or shape prevents their being grasped with the biopsy forceps or the polypectomy snare.

Protecting tubes in the oesophagus have previously been used during endoscopy when rigid instruments were used (Segal 1960; Boros, 1961). The plastic tube left in situ permitted the introduction of different instruments for the inspection of the whole stomach. The risk of oesophageal perforation was thus minimized.

\section{References}

Boros, E. (1961). American fournal of Gastroenterology, 35, 326.

Franke, K., Janzik, K., Richter, R., and Theuer, D. (1969). Chirurgie Praxis, 13, 239.

Jackson, C., and Jackson, C. L. (1951). Bronchoesophagology. Philadelphia, Saunders.

Maimon, H. N., and Milligan, F. D. (1972). Gastrointestinal Endoscopy, 18, 163.

Murat, J., et al. (1969). Lyon Chirurgie, 65, 880.

Ottenjann, R. (1970). Endoscopy, 2, 139.

Perelman, H. (1962). Fournal of Abdominal Surgery, 4, 57.

Rösch, W., and Classen, M. (1972). Endoscopy, 4, 193

Ségal, S. (1960). In Traite Pratique de Photographie et de Cinématographie Medicales, ed. P. Mantel, p. 200. Paris.

Spitz, L. (1971). British Medical fournal, 4, 469. 